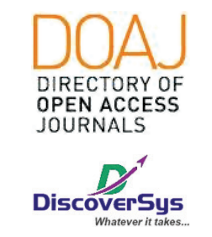

Published by DiscoverSys

\title{
The conventional management of periapical cyst caused by post-dental treatment failure: A case report
}

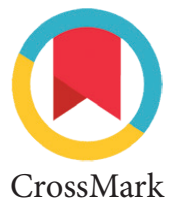

\author{
Florence Ariyana Manuputty, ${ }^{1 *}$ Sylvyana $\mathrm{M}^{1}{ }^{1}$ Tasman $\mathrm{A}^{1}$
}

\section{ABSTRACT}

Background: Periapical cyst is the typical type of cyst that found in dental practices. Periapical cyst is an advanced phase of dental infection due to caries. Untreated caries will leads to pulpitis and develop to pulp necrosis. Periapical cyst is formed following the necrotic pulp. This study aims to describe the conventional management by enucleation technique to periapical cyst due to post-dental treatment failure.

Case Description: A 22-years-old female patient came to oral and maxillofacial surgery clinic with a chief complaint of palatal swelling since eight months ago. On clinical examination, there was palatal swelling of $2 \times 1 \times 1 \mathrm{~cm}$ in size and radiograph showed a periapical cyst about pulp gangrene of teeth 21 and 22. Trauma history was found about 5 years ago with anterior teeth fractured and treated with restoration. The cyst was treated by enucleation and extraction was carried out for pulp gangrene teeth. There was no obturator insertion. The treatment showed a good prognosis and no secondary infection noticed.

Conclusion: The treatment of periapical cyst was successfully by nonsurgery conventional therapy with endodontic treatment and surgery method by enucleation for the bigger lesion. Cyst enucleation can be done without any complication, such as periodontal tissue damage.
${ }^{1}$ Oral and Maxillofacial Surgery Department, Faculty of Dentistry, Padjadjaran University, Dr. Hasan Sadikin General Hospital, Bandung, Indonesia
${ }^{*}$ Corresponding to: Florence Ariyana Manuputty, Oral and Maxillofacial Surgery Department, Faculty of Dentistry, Padjadjaran University, Dr. Hasan Sadikin General Hospital, Bandung, Indonesia.

florencemanuputty07@gmail.com

Diterima: 2018-05-19 Disetujui: 2018-07-5 Diterbitkan: 2018-08-1
Keywords: Conventional Management, Periapical Cyst, Post-Dental Treatment Failure,

Cite This Article: Manuputty, F.A., Sylvyana, M., Tasman. A. 2018. The conventional management of periapical cyst caused by post-dental treatment failure: A case report. Intisari Sains Medis 9(2): 165-167. DOI: 10.1556/ism.v9i2.269

\section{INTRODUCTION}

Cysts are sac-like structure of membranous tissue that contains fluid, air, or other substances which can occur in different places such as odontogenic cyst. ${ }^{1}$ Based on etiology, odontogenic cysts can be broadly divided into developmental and inflammatory types. Periapical or radicular cysts are the most common odontogenic cystic lesions of inflammatory origin. ${ }^{2}$ It can become quite large because of its ability for significant expansion, extension into adjacent tissues and rapid growth, and also has high recurrence rate. Periapical cyst is more frequent in the maxillary anterior region than mandible region. ${ }^{3}$

Most of the periapical cyst is symptomless and discovered when periapical radiograph is carried out. ${ }^{2}$ The patient often complains of slowly enlarging swellings. Periapical cysts and granulomas cannot be distinguished radiographically due to their appearance looks like a root-associated and well-defined radiolucency, as well as usually with a sclerotic bone in the periphery. However, periapical cyst appears as an oval or pear-shaped unilocular radiolucency in the periapical region radiographically. ${ }^{3}$ The signs and symptoms also similar in any circumstances such as infection due to poor dental treatment in the past.
Many treatment options, including apical surgery, have been proposed for eradicating several cases. ${ }^{4}$ However, the treatment options for periapical cyst can be conventional root canal therapy when lesion is localized and small or surgical treatment like enucleation when lesion is large. ${ }^{4}$ This study aims to describe a conventional management of periapical cyst case caused by post-dental treatment failure.

\section{CASE REPORT}

A 22-year-old female patient without systemic abnormality came with a complaint of intraoral swelling since two months (Figure 1). There was a history of trauma to the upper anterior teeth 5 years ago. She consulted a dentist and had a tooth restoration, but after a few years, the swelling appears. Since there was no improvement, the patient went to Oral and Maxillofacial Surgery Department at Dr. Hasan Sadikin Hospital for a medical check-up. The routine preoperative clinical examination was performed. According to clinical examination, the patient was asymptomatic, afebrile, and her blood pressure still within normal limits. Then the additional investigations 

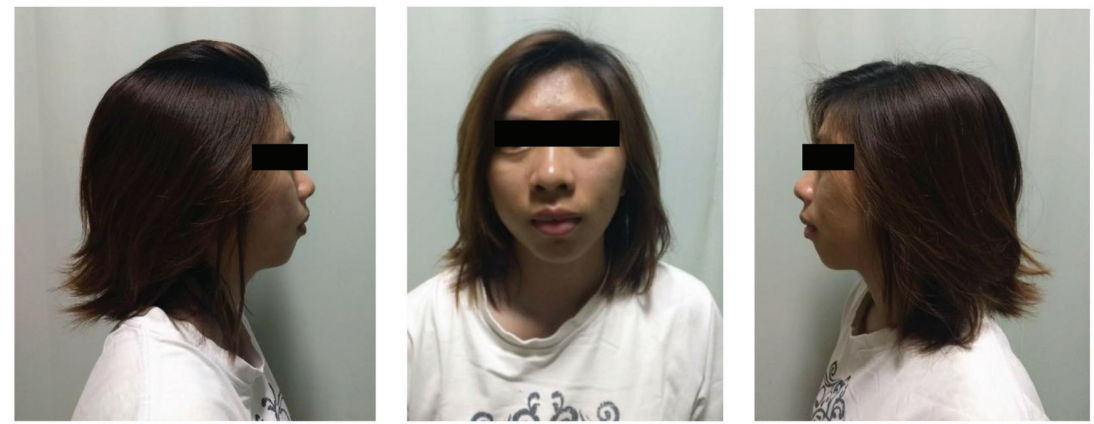

Figure 1 The profile picture of patient with periapical cyst
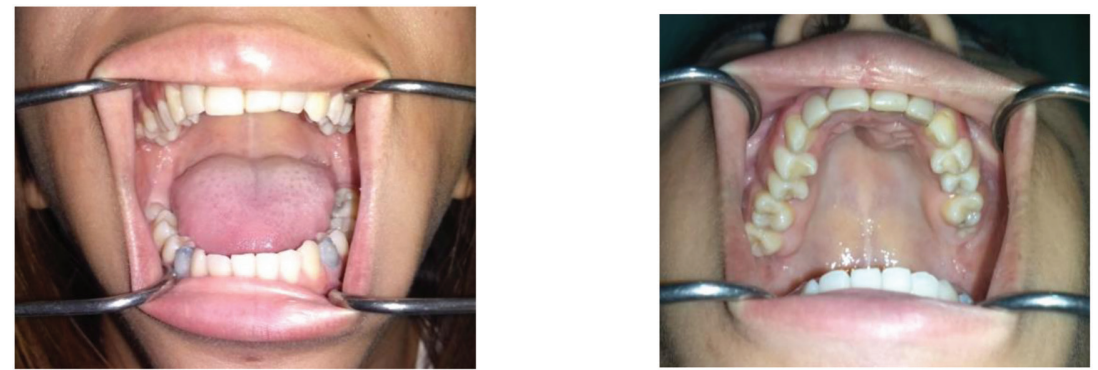

Figure 2 Intraoral presentation of periapical cyst

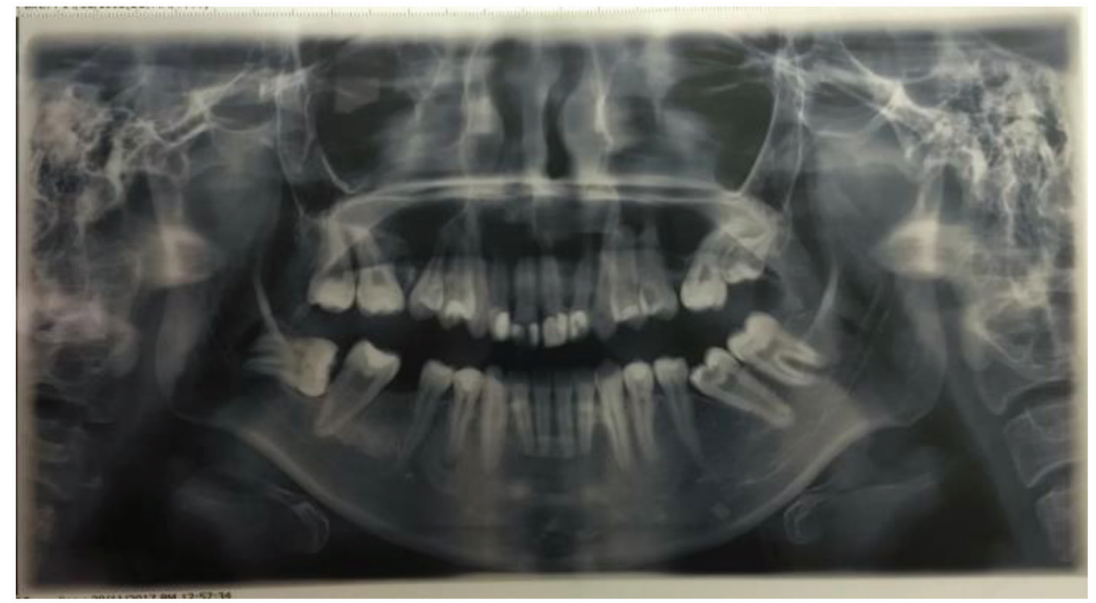

Figure 3 Intraoral panoramic of periapical cyst

such as complete blood test, thorax photos, and panoramic photos were carried out.

Based on intraoral examination a swelling was present in the palatal region, extending from 21 to 22 regions with the area of measuring $1.5 \times 1 \mathrm{~cm}$. On palpation, the lesion was soft to firm in consistency and tender. The mucosa overlying the swelling is normal in color and texture. Electric and thermal pulp vitality testing showed a negative response in 21 and 22 (Figure 2).

Panoramic photographs present oval shape periapical radiolucency about $3 \mathrm{~cm} \times 2 \mathrm{~cm}$ associated with 21-23 teeth (Figure 3).

Based on anamnesis, clinical and additional investigations, the clinical diagnosis of periapical cyst was carried out. After the diagnosis has been

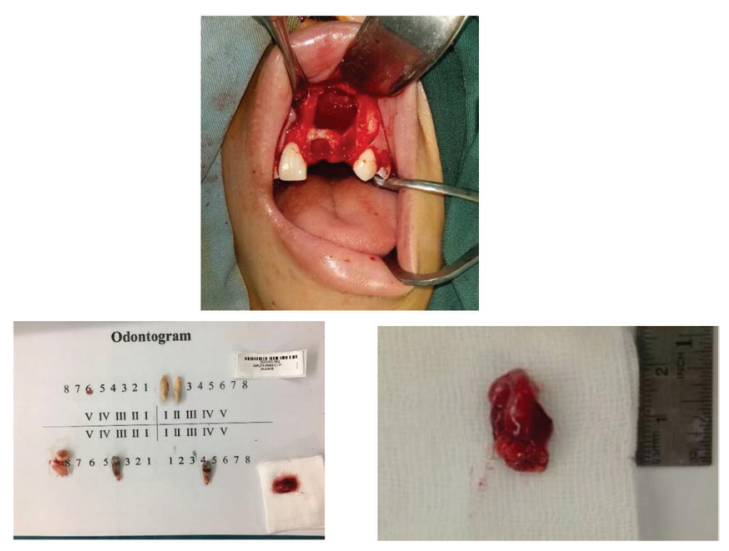

Figure 4 Surgery durante images of periapical cyst

made, the procedural treatment was conducted immediately. The patient admitted to the operating theater for definitive treatment with enucleation. After administration of general anesthesia, incision was given in palatal region which extends from 11 to 23 regions. A full thickness mucoperiosteal flap was reflected and irrigated with normal saline. Sizeable palatal bone resorption was present on the site. Complete curettage and enucleation of cyst done. Complete curettage was done and granulation tissue was removed.

\section{DISCUSSION}

Radicular cyst also known as periapical cyst, periodontal cyst, root end cyst or dental cyst, originates from epithelial cell rests of malassez in periodontal ligament as a result of inflammation due to pulp necrosis or trauma. ${ }^{5}$ Pathogenesis of periapical cysts has been described as comprising of three distinct phases: the phase of initiation, the phase of formation and the phase of enlargement. Initiation is mostly from the odontogenic epithelium. ${ }^{6}$ Cell rests of Malassez in the periapical got stimulation from the pulpal infection and they cause proliferation of the epithelium and form cellular arcades at periapical region. ${ }^{6,7}$ A key factor, which may initiate the inflammation and immune response and may directly cause epithelial proliferation, is now thought to be bacterial endotoxins released from the necrotic pulp and triggering cavity-formation to be lined by the proliferating odontogenic epithelium. ${ }^{8}$ The infection initiates periapical cyst could be related to poor dental treatment in the past due to traumatic injuries. ${ }^{9}$

Periapical cysts are usually asymptomatic until detected by routine radiographic examination where an acute exacerbation of the cystic lesion develops signs and symptoms such as swelling, tooth mobility and displacement of an unerupted tooth. ${ }^{10}$ The clinical, radiographic and microscopic features 
of the case described support a diagnosis of the periapical cyst. A conservative therapy successfully treated the periapical cyst. The enucleation technique described is similar to the study performed by Delbem et al. but the authors used removable resin tube instead of using fix tube. ${ }^{11}$ Some advantages are offered by a conventional technique such as: 1) Better prevention of cystic cavity from food accumulation and 2) good patient compliance. In conclusion, this conventional approach is effective for the treatment of a wide range of periapical cysts in primary teeth.

\section{CONCLUSION}

The conventional management by enucleation technique for a periapical cyst in the case of post-dental treatment failure exhibit a good prognostic for the patient. Early-appropriate management is necessarily important to prevent the progression of this disease.

\section{REFERENCES}

1. Shear M. Cysts of the oral regions. 3rd ed. Boston: Wright, 1992, 136-70

2. Jansson L, Ehnevid H, Lindskog S, Blomlöf L. Development of periapical lesions. Swedish Dental Journal 1993; 17(3):85-93
3. Deshmukh J, Shrivastava R, Bharath KP, Mallikarjuna R. Giant radicular cyst of the maxilla. BMJ Case Rep. 2014. doi:10.1136/bcr-2014-203678

4. Kim S, Kratchman S. Modern endodontic surgery concepts and practice: A review. J Endod. 2006;32:601-23

5. Valois CR, Costa-Júnior ED. Periapical cyst repair after nonsurgical endodontic therapy - case report. Braz Dent J 2005; 16(3):254-8

6. Lustmann J, Shear M. Radicular cysts arising from deciduous teeth: Review of the literature and report of 23 cases. International Journal of Oral Surgery 1985; 14(2).

7. Jansson L, Ehnevid H, Lindskog S, Blomlöf L. Development of periapical lesions. Swedish Dental Journal 1993; 17(3):85-93.

8. Mass E, Kaplan I, Hirshberg A. A clinical and histopathological study of radicular cysts associated with primary molars. J Oral Pathol Med. 1995; 24:458-61.

9. Demeter A, Bogdán S, Tóth Z, Nemes J. Complex treatment of a large radicular cyst due to traumatic dental injury--a case report. Fogorv Sz. 2014;107(1):29-33

10. Gandhi S, Franklin DL. Presentation of a radicular cyst associated with a primary molar. European Archives of Paediatric Dentistry. 2008;9(1):56-59

11. Delbem AC, Cunha RF, Vieira AE, Pugliesi DMC. Conservative treatment of a radicular cyst in a 5-year-old child: a case report. Int J Paediatr Dent 13: 447-450, 2003

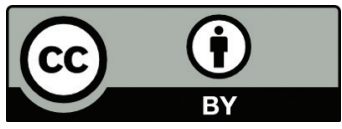

This work is licensed under a Creative Commons Attribution 